\title{
Can we predict the appearance of the most virulent Covid-19 outbreaks in the world?
}

\author{
José Vidal-Gancedo* and Vega Lloveras \\ Instituto de Ciencia de Materiales de Barcelona (ICMAB-CSIC); Campus UAB s/n, 08193 \\ Bellaterra, Barcelona (Spain) and CIBER de Bioingeniería, Biomateriales y Nanomedicina, \\ CIBER-BBN, Barcelona (Spain). \\ e-mail:j.vidal@icmab.es
}

\begin{abstract}
The Covid-19 pandemic has spread throughout the world at great speed, however, its capacity for expansion and therefore its impact on a country's health system and its economy is not the same in the different areas of the world. In this work, we present a study on the influence of temperature on the speed of virus transmission. The study has been carried out with data collected in a narrow time window, one month, and from a reduced geographical area such as a single country, as Spain, or a cruise such as the Diamond Princess. The objective is to have the data as homogeneous as possible and try to minimize the influence of factors that are not strictly environmental. The result is that there is a clear relationship between the temperature and the speed of virus spread.
\end{abstract}

\section{Introduction}

The Covid-19 pandemic has spread around the world at a dizzying speed, however, its capacity to expand and therefore its incidence on a country's health system and economy is not the same in some areas of the Earth as in others. It also seems clear that, until there is an effective medicine against the SARS-CoV-2 virus or the much-desired vaccine is obtained, the only way to fight its spread is to prevent contagion between people. Therefore, it is essential to know the mechanisms of contagion and to carry out hygienic measures, social distancing, confinement, etc., as effective as possible.

One of the characteristics of this pandemic is that there is more and more data available with which epidemiologists will undoubtedly be able to study and get to know the disease in depth in the future. The problem is that its expansion is so rapid that there is no time to lose, and it is essential to analyse the data as soon as possible in order to predict its behaviour and be able to evaluate for a given country, where and when the most virulent outbreaks are most likely to occur, try to slow down their evolution and ensure that the health system does not collapse or that containment measures do not drastically affect the economy.

Unfortunately, we are witnessing a proliferation of data on Covid-19 that is so great that it surpasses us. As well as having a lot of data, the way in which it is presented differs in each country so that it is not easy to compare it and draw conclusions other than in a very general way. Furthermore, the data must be given for a fixed number of inhabitants, for example, per 100,000, in order to be comparable. The problem is very complex as there are many factors that can influence the incidence of the disease. From those that depend on personal characteristics (age, sex, previous pathologies...) to those others that affect the speed of propagation (mechanisms and routes of contagion, population density, pollution...). Among the latter, one of the factors that can help us is the possible 
relationship between the environmental conditions of each country and the speed of propagation of the virus.

In the last days, scientific articles (1) and opinion articles (2) have been appearing in the media warning of the incidence of environmental conditions on the speed of propagation of the coronavirus, but this fact does not seem to have much influence on the strategic planning carried out in each country to contain the spread of the pandemic. However, environmental conditions and, above all, temperature may play a fundamental role in its incidence.

\section{Results and discussion}

From the studies published so far, it seems clear that the optimal conditions for the coronavirus propagation occurs in a narrow range of temperatures, between 4 and $11{ }^{\circ} \mathrm{C}$ and in a medium-low humidity, while at lower or higher temperatures its ability to propagate is lower.

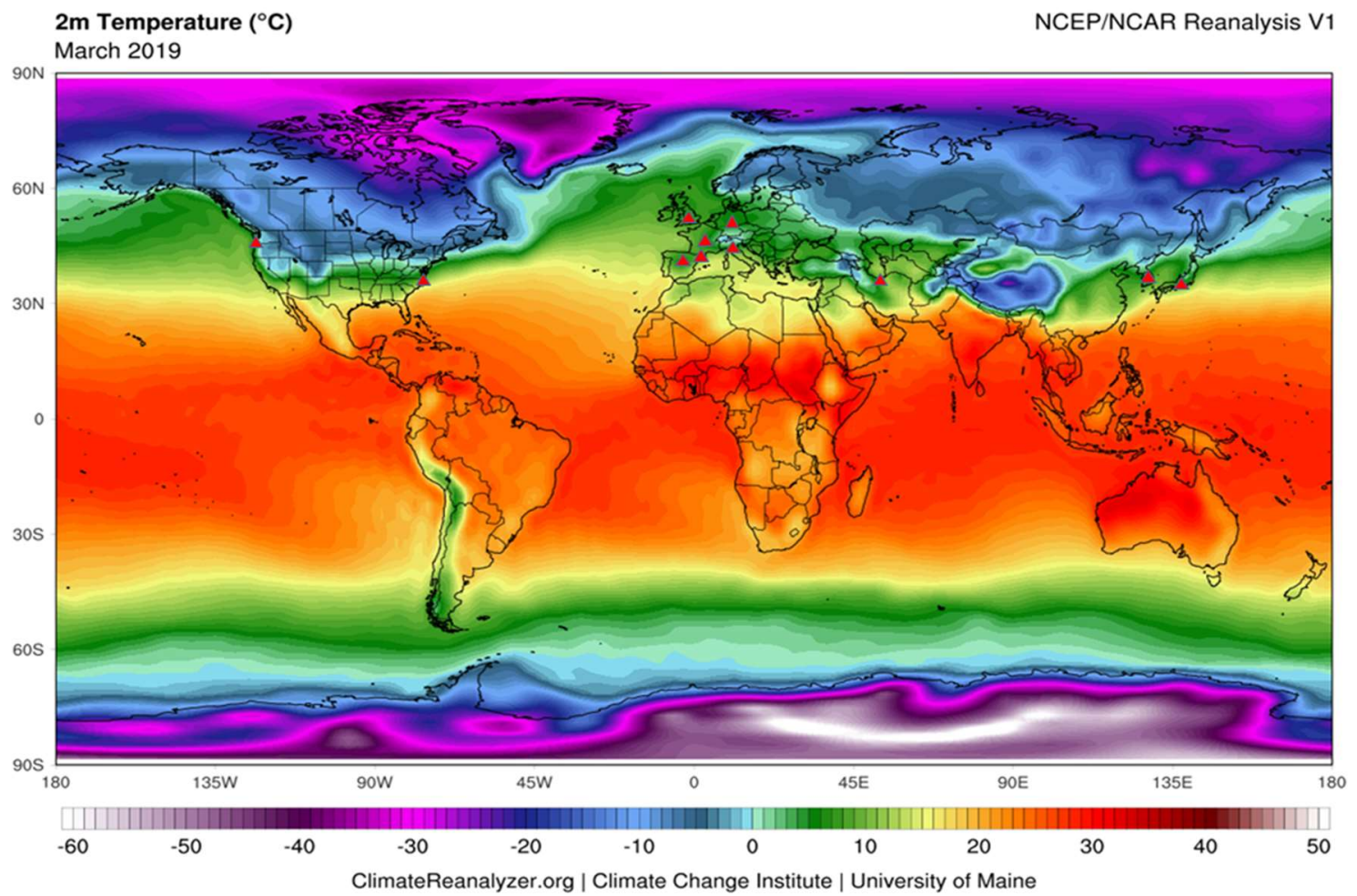

Figure 1: Map of the average temperatures in the world for March 2019.

(1) a) Mao Wang, Aili Jiang et al. Temperature significant change COVID-19 Transmission in 429 cities. 2020. https://www.medrxiv.org/content/early/2020/02/25/2020.02.22.20025791. b) Sajadi, M.M., et al. Temperature and Latitude Analysis to Predict Potential Spread and Seasonality for COVID-19. SSRN. 2020 doi.org/10.2139/ssrn.3550308. c) Alessio Notari. Temperature dependence of COVID-19 transmission. https://www.medrxiv.org/content/10.1101/2020.03.26.20044529v1.full.pdf.d) Miguel B. Araújo and Babak Naimi. Spread of SARS-CoV-2 Coronavirus likely constrained by climate. 2020. medRxiv preprint https://doi.org/10.1101/2020.03.12.20034728. e) Jingyuan Wang, Ke Tang, Kai Feng and Weifeng Lv. High Temperature and High Humidity Reduce the Transmission of COVID-19. SSRN: http://dx.doi.org/10.2139/ssrn.3551767. f) Aurelio Tobías, Tomás Molina. Environmental Research DOI: https://doi.org/10.1016/j.envres.2020.109553.

(2) a) José Vidal Gancedo. ¿Se acabará la pandemia con la llegada del buen tiempo? La Vanguardia 28/04/2020. Pag. 30. b) Richard Gray. Will warm weather really kill off Covid-19? BBC. 24th March 2020. 


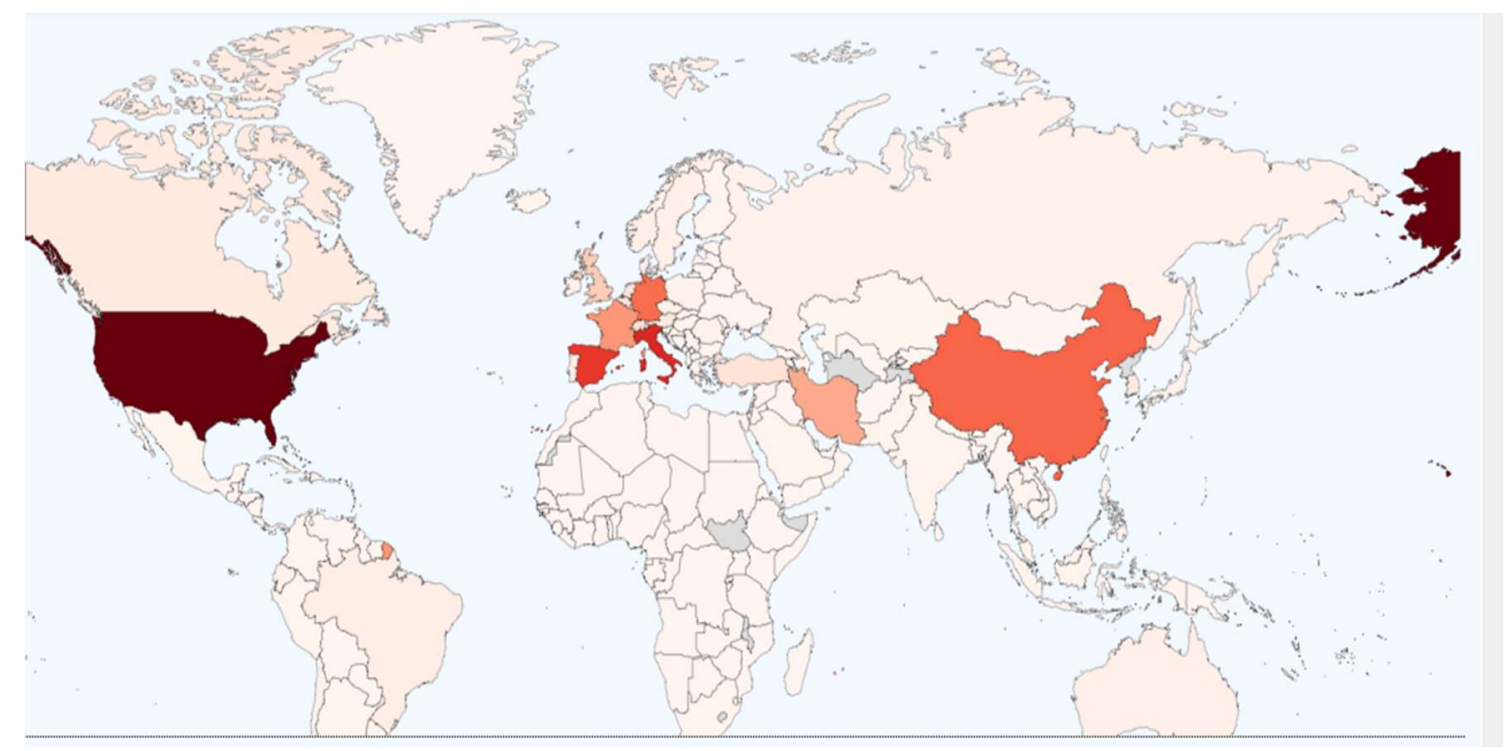

Figure 2: Total number of cases by country on 31 March 2020. RTVE.

Figure 1 shows the map of average temperatures in the world for March 2019 (3) and Figure 2 shows the distribution of the number of cases in each country at 31 March 2020 (4). As the 2020 temperature data is not yet available and the temperature distribution is similar year after year, we can use the data from March 2019 to carry out the study. A comparison between both figures shows the close relationship between a narrow temperatures range $\left(4-11^{\circ} \mathrm{C}\right.$, green area of Figure 1) and the most affected countries (Figure 2). Indeed, as the pandemic spread around the world, the most virulent outbreaks were distributed over such narrow strip of the northern hemisphere with similar environmental conditions: first China, then Iran, South Korea, and Italy. Then France, England, Germany, Spain, the United States, Turkey... all in the green area of Figure 1. The corresponding temperature range in the southern hemisphere hardly passes through populated areas.

Although meteorological data are well documented, the same cannot be said of the data that countries are providing on the incidence and distribution of the epidemic in their territory. In order to minimize dispersion and have as homogeneous data as possible, it is necessary to stick to a single country that can be representative. One country that meets the requirements for this study is Spain.

In Spain, the incidence of Covid-19 is very high, so we have many cases distributed throughout the country. With the detection of the first cases of infection in February, an exhaustive follow-up of the imported cases was made until from the beginning of March many of the infections became local with an important growth day after day. The expansion of the pandemic was so fast that in one month it went from 32 cases to 95,000 with more than 8,000 deaths.

(3) Climate Reanalyzer, Climate Change Institute. University of Maine, EE. UU.

https://climatereanalyzer.org/reanalysis/monthly maps/

(4) https://www.rtve.es/noticias/20200324/mapaymundialydelycoronavirus/1998143.shtml 
Spain is a country with a model and well established health system all over its geography to cope with the pandemic, and we can say that the way to detect new cases of infection and their treatment it is the same in all the country. In addition, the Spanish government has been taking decisions that affect the whole territory in a homogeneous way so that the differences in the spread of the pandemic can be attributed more to generic conditions rather than to other factors of spread which, in theory, should affect all communities equally. Finally, Spain has significant climatic differences between regions and during the months of February and March its average temperature is in the range of temperatures that we assume optimal for the spread of the virus, so that the difference in environmental conditions between different areas of the country would have to correlate well with the evolution of the pandemic. Another important issue to take into account is that until March 15 the state of alarm was not established, so the influence on the evolution of the pandemic due to the confinement of the population was minimal. Moreover, if we take into account that the incubation time of the disease and the appearance of the first symptoms can range from two to fourteen days, it is expected that until the end of March the effects of the population confinement will not have a large influence. For this reason, we have a period of time of approximately one month to study the free evolution of the pandemic without any other limit than the general factors such as temperature.
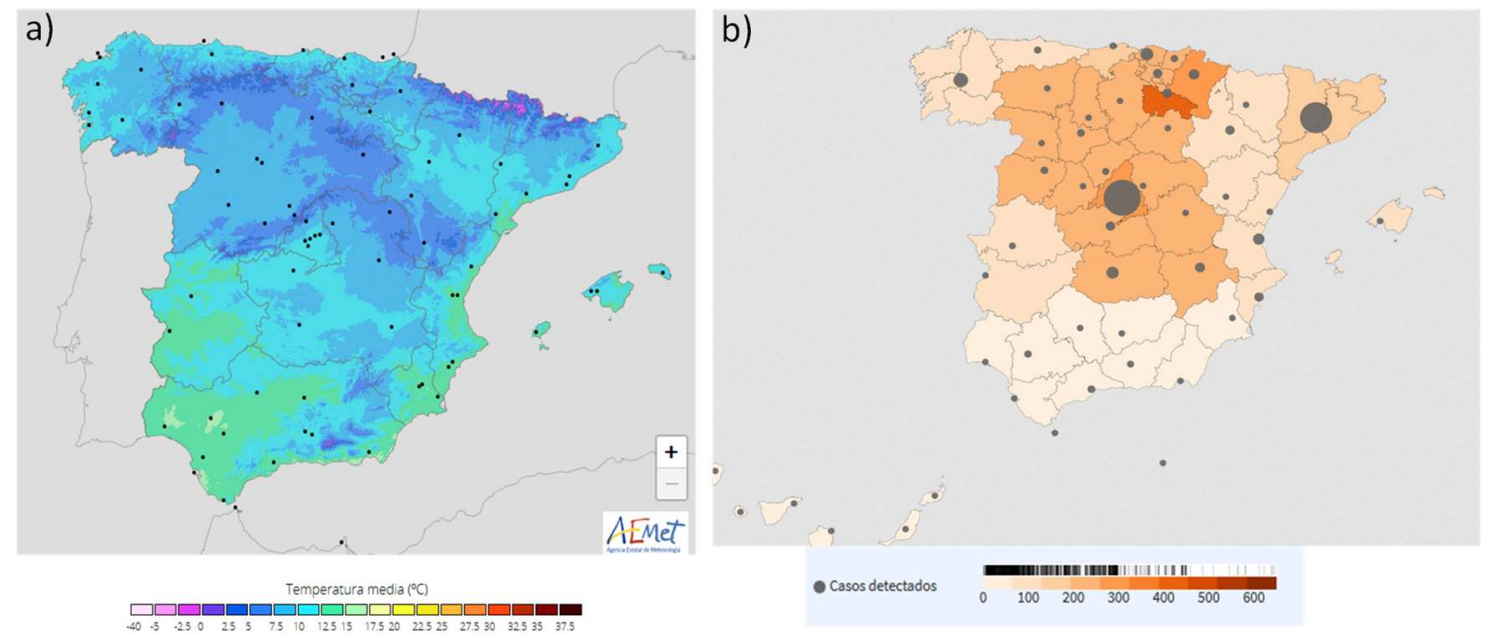

Figure 3: a) Average temperature of March 2019 in Spain. b) Cumulative incidence per 100,000 inhabitants for the last 14 days as of March 31, 2020.

Figure 3a shows the map of average temperature in Spain during March 2019 published by the State Meteorological Agency, AEMET (5). It can be appreciated the important difference in average temperature between the center and north of the peninsula ( 0 to 10 ${ }^{\circ} \mathrm{C}$ ) and the coast in general, and in particular with respect to the Mediterranean coast and Andalusia $\left(12{ }^{\circ} \mathrm{C}\right.$ to $\left.20^{\circ} \mathrm{C}\right)$. Moreover, in the Canary Islands the average temperature is even higher.

Figure $3 \mathbf{b}$ shows the accumulated incidence of cases per 100,000 inhabitants on average over the last 14 days (AI) at March 31, 2020 (6). A good correlation can be observed between the most affected areas (Figure 3b) and the optimum temperature area for the spread of the virus, between 4 and $11^{\circ} \mathrm{C}$ (Figure 3a). In fact, in the Spanish central

(5) http://www.aemet.es/es/serviciosclimaticos/datosclimatologicos/valoresclimatologicos

(6) https://www.rtve.es/noticias/20200420/mapa-del-coronavirus-espana/2004681.shtml 
plateau and the highest areas of the north of Spain (Castilla y León, Castilla La Mancha, Madrid, La Rioja, Navarra, the Basque Country, Catalonia, etc.) almost all the communities exceed an AI of 250 cases per 100,000 inhabitants, while in warmer areas of the east and south they tend to fall below 100. A clear example is the difference between two neighbouring communities with a marked difference in temperature, such as Castilla La Mancha and Murcia, where the former has a fivefold increase in the number of cases with no apparent difference other than temperature. If we take into account the number of deaths per 100,000 inhabitants, the difference is even greater: 38 compared to 2.5. To better illustrate this relationship, Figure 4 shows the evolution of Covid-19 in all regions of Spain except Ceuta and Melilla, collected by the author during the month of March 2020 from the daily reports published by the Health Alert Coordination Centre of the Ministry of Health of the Spanish Government (7). Each data series is labeled with the name of the Autonomous Community and the historical average temperature for the month of March of a representative city of each one (8). The picture clearly shows the great difference in the incidence of the pandemic in the different communities, which also correlates very well with its average temperature during the month of March depicted in Figure 3a. In addition, as can be observed in the inset of Figure 4, there is a good correlation between the different communities historical average temperature in March and the accumulated incidence (AI) of each one. The higher average temperature the lower AI.

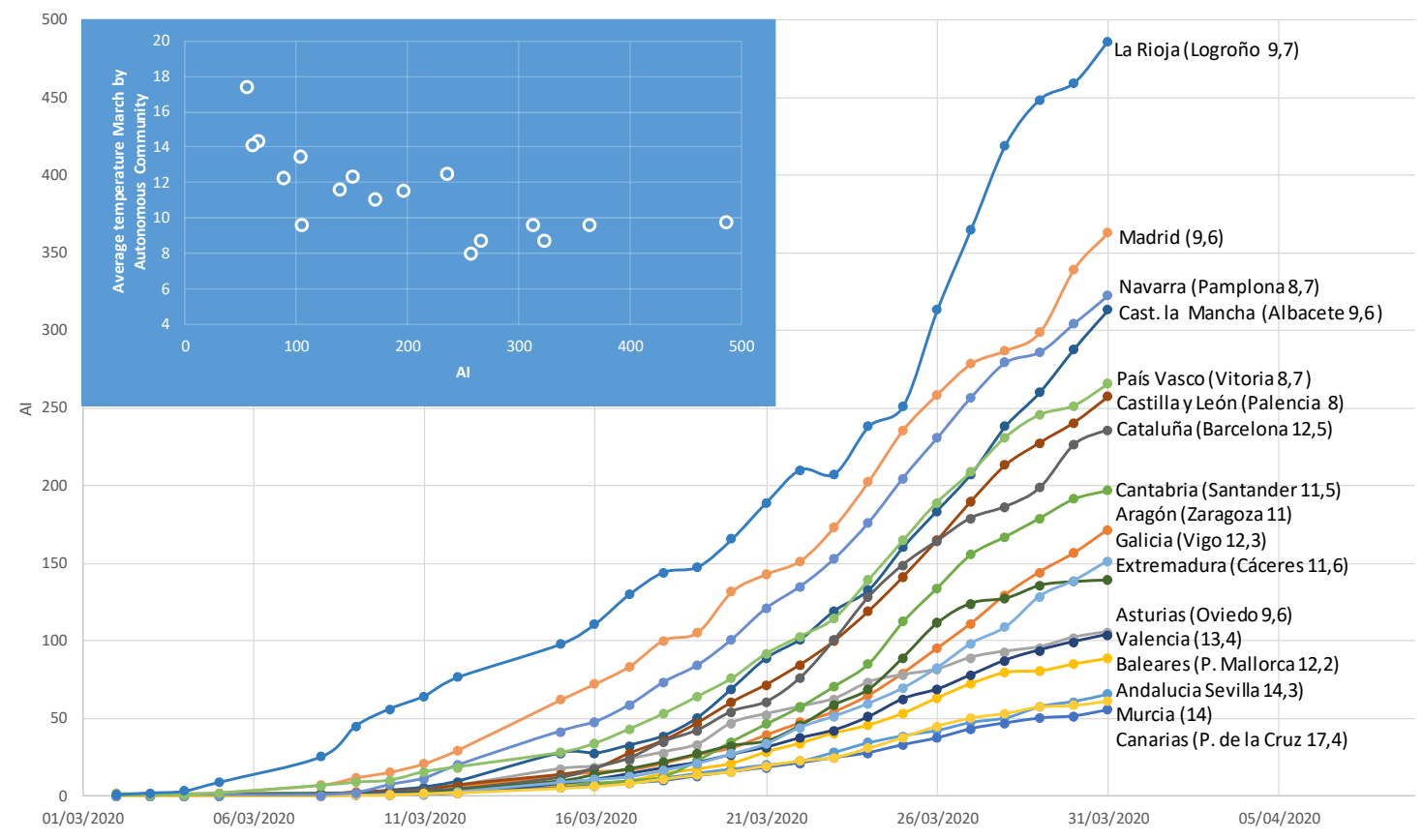

Figure 4: Average cumulative case incidence per 100,000 inhabitants for the last 14 days (AI) during the month of March 2020. The historical average temperature for the month of March in a representative city of each Community is shown. The inserted graph shows the relation of the historical average temperature in March against the AI of each Community.

(7) https://www.mscbs.gob.es/profesionales/saludPublica/ccayes/alertasActual/nCovChina/documentos.htm

(8) https://es.climate-data.org/europe/espana-5/ 
If we focus on a smaller area, for example, one of the Autonomous Communities, the orography and temperature data can be represented in more detail and related to the pandemic data on a smaller scale.

We have chosen two representative regions: Catalonia and Andalusia. Both have a complex orography and a sufficient number of inhabitants for the study to be representative. In both cases, their territory ranges from sea level to mountainous areas with altitudes above 3,000 $\mathrm{m}$ offering a wide range of temperatures. The difference is that Catalonia is in the north of Spain while Andalusia is in the south of the country.

Figure 5a shows the average temperature map of Catalonia during the month of March 2020 published by AEMET (9), while Figure 5b shows the number of cases per 100,000 inhabitants by region on April 10, 2020 published by the Generalitat de Catalunya (10). Although the orography is complex, it can be seen that, apart from the most populated regions, in general, the highest incidence occurs in areas where the average temperature is between 4 and $10^{\circ} \mathrm{C}$, with very high incidence of the pandemic, ranging between 300 and 600 cases per 100,000 inhabitants. By contrast, in the south of Catalonia, with milder temperatures, the incidence (AI) is less than 100 cases.
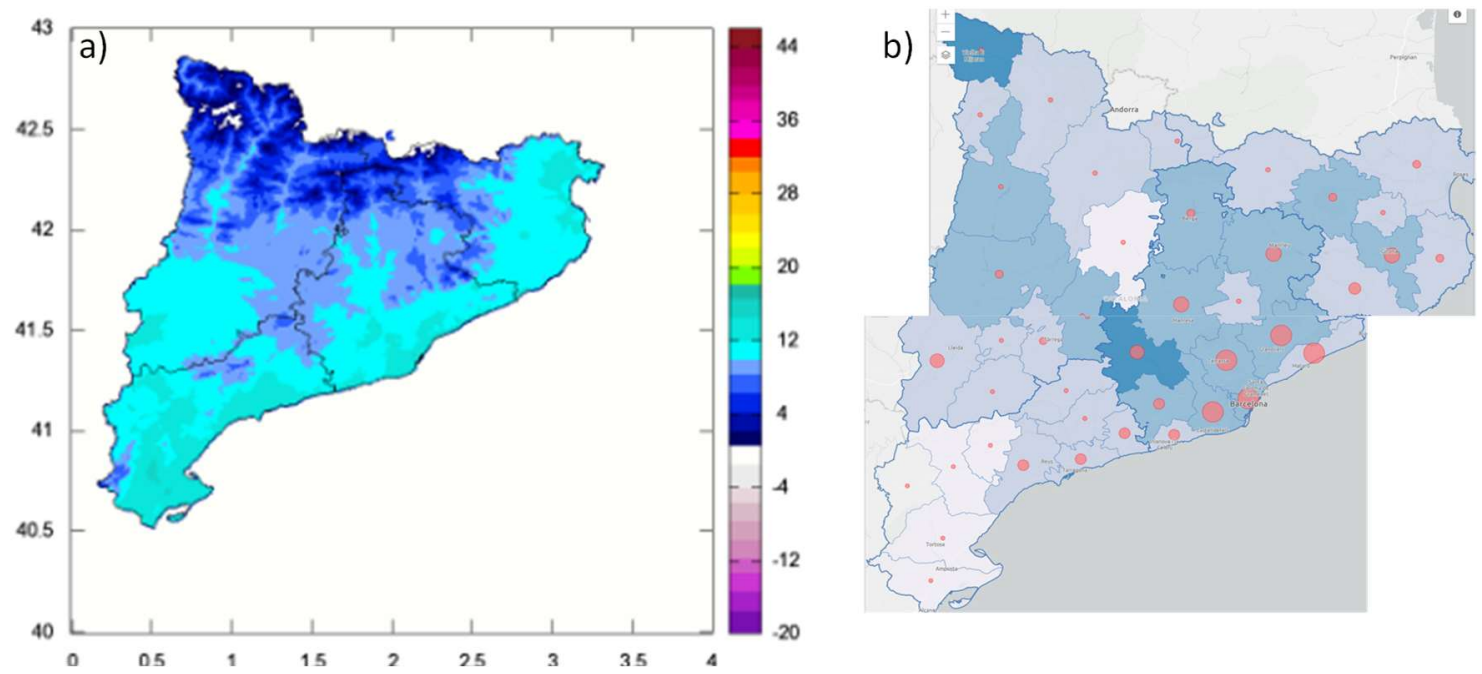

Figure 5. a) Average temperature map of Catalonia during the month of March 2020 published by AEMET. b) Number of cases per 100,000 inhabitants by region on 10 April 2020 published by the Generalitat de Catalunya.

On the other hand, Figure 6a shows the map of average temperature in Andalusia during the month of March 2020 published by the AEMET (11), while Figure 6b shows the number of cases per 100,000 inhabitants by province at April 9, 2020 published by the Andalusian Government (12). In this case, the fundamental difference with Catalonia is that the average temperature range is between 12 and $18{ }^{\circ} \mathrm{C}$, except in the most mountainous areas. Comparing both figures, we can observe that the number of cases is

(9) http://www.aemet.es/es/serviciosclimaticos/datosclimatologicos/valoresclimatologicos

(10) http://aquas.gencat.cat/ca/actualitat/ultimes-dades-coronavirus/mapa-per-municipis/

(11) http://www.aemet.es/es/serviciosclimaticos/datosclimatologicos/valoresclimatologicos

(12) http://www.juntadeandalucia.es/institutodeestadisticaycartografia/salud/COVID19.html 
higher in the colder provinces while it decreases as we go to warmer areas. In any case, the extent of the pandemic ranges from 50 to 185 cases per 100,000 inhabitants. This is considerably lower than in Catalonia.

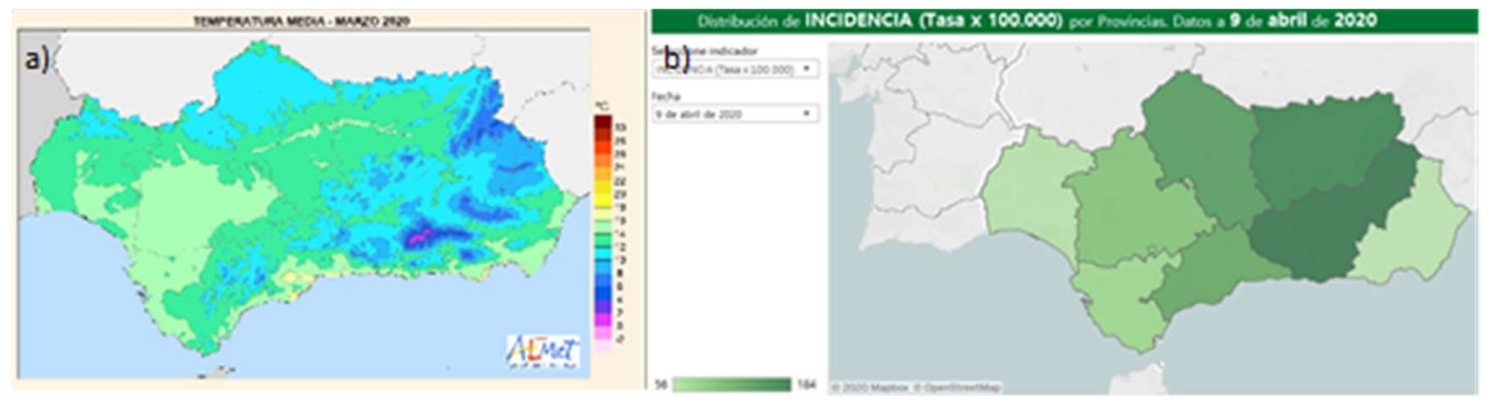

Figure 6. a) Average temperature map of Andalusia during the month of March 2020, published by AEMET. b) Number of cases per 100,000 inhabitants by province at 9 April 2020, published by the Andalusian Government

Finally, there are particular cases in which the external climatic conditions can be dramatically changed in a short period of time, as is the case of a cruise. A big ship is like a small city and it has all the characteristics and casuistry of virus transmission that can be found in a city, with the particularity that you can choose to navigate through areas with different environmental conditions. Recently, an exhaustive study has been published (13) about the case of the Diamond Princess Cruise. This article suggests that SARS-CoV-2, may not travel much in the air in open spaces. However, if we analyze the facts described, the conclusion could be different.

On January 20, a passenger who came from the area of Hong Kong and China joined the cruise in Yokohama, Japan. He had been coughing for one day and on January 23, he began to have a fever. The passenger disembarked in Hong Kong port on January 25 and on February 1 it was confirmed he had the Covid-19. The ship was quarantined on February 5, upon arrival in Yokohama, with 2,666 passengers, and they were asked to remain in their cabin because several passengers had developed the disease. On March 1, the confinement finished with 699 cases detected (13).

The wave of infections was associated with a reproduction number (R0) of 11 . This high reproduction number can be explained by the fact that a cruise ship has many people in small spaces with many opportunities for mass gatherings in swimming pools, casinos, theatres, etc.

The interesting thing about this case is that, apart from several infections through direct contact with the affected passenger, the indiscriminate infection began to be detected at the beginning of February. According to the calculus made by the authors of the work, the massive infections began on January 28, 8 days after the passenger considered to be the origin of the outbreak disembarked. None of the passengers who disembarked between January 27 and 31 developed the disease. The question that remains in the air is:

(13) Pengcheng Xu, Hua Qian, Te Miao, Hui-Ling Yen, Hongwei Tan, Min Kang, Benjamin J. Cowling, Yuguo Li. Transmission routes of Covid-19 virus in the Diamond Princess Cruise ship. medRxiv. https://doi.org/10.1101/2020.04.09.20059113 
why did the mass infections started so late, when there were already several cases on board?

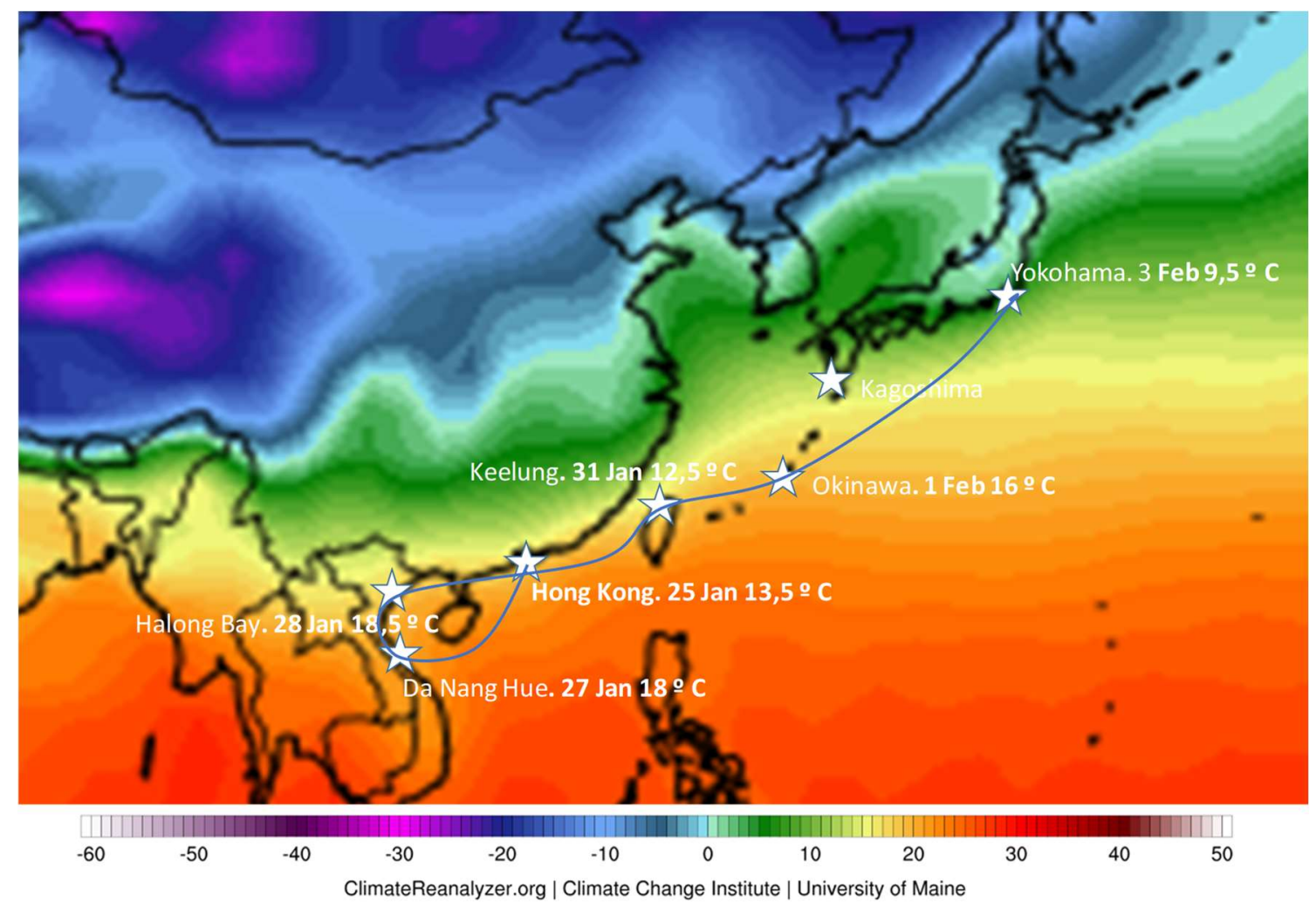

Figure 7. Route of the cruise ship between Hong Kong (25 January) and Yokohama (3 February) with cities, date and actual average temperature at each point drawn over a map with the average temperature of March 2019, to illustrate the journey.

If we look closely at the route of the cruise ship, it left Yokohama, Japan on January 20, heading for Hong Kong via Kagoshima (southern Japan). From Hong Kong (January 25) the ship went to Vietnam, Da Nang Hue, (January 27), Halong Bay, (January 28), then to Keelung, in Taiwan (January 31), coming back to Japan through Naha, Okinawa (February 1) and ending in Yokohama (February 3). The entire journey through Hong Kong, Vietnam and Taiwan was through warm areas (Figure 7). Only on the way back to Japan the ship sailed into colder waters. After leaving the island of Okinawa behind, it entered the area with the highest risk of active outbreaks, according to the temperature (green area). This corresponded to about February 2 or 3, just when the authors have calculated the maximum peak of infections. Could it be a coincidence? The average temperature for the first five days of February 2020 in Yokohama was $9.5^{\circ} \mathrm{C}$, the coldest region of the journey.

In conclusion, it has been shown that the influence of temperature on the rate of expansion of Covid-19 is an important factor to take into account in order to understand the behaviour and spread of the disease on the planet and may justify the great differences in the behaviour of the pandemic depending on the environmental conditions of each country. The temperature seems to be directly related to the appearance of very active shoots, defined by a high transmission capacity and a very fast growth in short periods of time. When this happens, if action is not taken very quickly the consequences are catastrophic: very rapid increase in the number of cases and number of deaths, collapse 
of the health systems and the need to extreme and prolong in time the measures of confinement with the consequent economic collapse of the country.

We now have tools for predicting climatic conditions throughout the year and therefore we can predict in which countries or regions of a country the probability of appearing the most active disease outbreaks is highest. In this way, the most appropriate measures can be applied in advance to contain the pandemic, optimize health resources and minimize the effects that total confinement of the population could have on the economy.

Over the coming weeks and months, we can venture that the capacity for contagion will decrease in Spain as the optimal temperature range for the virus propagation moves to the north. On the contrary, the optimal temperature zone will be moving through the European Nordic countries and in central and northern Russia, while in North America it will move between the northwest and north of the USA and southern Canada. In addition, as winter progresses in the southern hemisphere, areas such as southern Chile and Argentina, South Africa and southern Australia could experience significant outbreaks, not forgetting what can happen when winter returns to the northern hemisphere.

We declare no competing interests.

We thank Dr. Anna May-Masnou (ICMAB-CSIC) for her technical support and fruitful discussions. 